American Journal of Applied Sciences 8 (11): 1107-1115, 2011

ISSN 1546-9239

(C) 2011 Science Publications

\title{
Impact of Dispositional Factors and Work-Family Conflict on Job Satisfaction among Single Mother Employees
}

\author{
Aminah Ahmad and Noryati Ngah \\ Department of Professional Development and Continuing Education, \\ Faculty of Educational Studies, University Putra Malaysia, \\ 43400 UPM Serdang, Selangor, Malaysia
}

\begin{abstract}
Problem statement: Few studies have tested the indirect effects of dispositional factors including perfectionism and locus of control on job satisfaction through work-family conflict. Approach: This study examined the indirect effects of perfectionism and locus of control on job satisfaction through work-family conflict. The sample consisted of 159 single mother employees. Data were gathered using self-administered questionnaires. The data were analyzed using structural equation modeling procedure to determine if the hypothesized model fit the data. Results: The results showed that perfectionism and locus of control were significantly related to work-family conflict and that work-family conflict in turn was related to job satisfaction. The results support the indirect path between locus of control and job satisfaction through work-family conflict. The indirect path between maladaptive perfectionism and job satisfaction through work-family conflict was also supported. Conclusion: This study establishes the presence of indirect effects of maladaptive perfectionism and internal locus of control on job satisfaction through work-family conflict and verifies that maladaptive perfectionism and internal locus of control can result in work-family conflict which can consequently lead to a reduction in job satisfaction.
\end{abstract}

Key words: Perfectionism, locus of control, work-family conflict, job satisfaction

\section{INTRODUCTION}

In Malaysia, women's participation in the labor force rose steadily from $44.7 \%$ in $1995-46.4 \%$ in 2009 Department of Statistics, Malaysia, 2009. An important feature of this change is the increase in the participation of married women and single mothers in employment. Slightly more than half $(59.4 \%)$ of the total women employed in 2009 were married and the labor force participation rate of single mothers in Malaysia was $7.4 \%$ in 2009 compared with $6.6 \%$ in 2005 Department of Statistics, Malaysia, 2009. Unlike men, women tend to spend more time in childcare and they perceived themselves as responsible for childcare activities at home besides their responsibilities at the workplace (Bergman et al., 2008). With multiple roles, there is a greater likelihood that the female employees would experience conflict between work and family roles as shown in studies conducted in Malaysia (Ahmad and Omar, 2008; 2010). As employment among single mothers appears to be a vital source of economic security, studies which examine the interface between work and family roles seem especially important. However, studies among female employees tend to exclude single mother employees since including them could be less manageable as compared to larger categories of married women, never-married women, or wives of employed men.

Previous research findings have shown that one of the negative outcomes of work-family conflict is job dissatisfaction (Howard et al., 2004; Gordon et al., 2007; Hill et al., 2004). Job satisfaction is one of the most widely studied variables in organizational research because of its well-established impact on many job outcomes, including job performance, job stress, emotional exhaustion, life stress and turnover intention (Ahmadi and Alireza, 2007; Yahaya et al., 2009; Chen et al., 2011; Rehman, 2011). However, to date there is very limited research on the indirect effects of dispositional factors including perfectionism and locus of control on job satisfaction via work-family conflict. With regard to work-family conflict in terms of its antecedents and outcomes, a number of previous research on this topic were mainly based on samples

Corresponding Author: Aminah Ahmad, Department of Professional Development and Continuing Education,

Faculty of Educational Studies, University Putra Malaysia, 43400 UPM Serdang,

Selangor, Malaysia Tel: +60389468225 Fax: +60389450455 
derived from the developed Western countries and research on samples from developing countries have been underrepresented. In addition, most of the research has been conducted among dual career couples with a lack of focus on single mother employees. Hence, investigating dispositional factors on work-family conflict and the effect of this conflict on job outcome, such as job satisfaction, of single mother employees using samples from developing countries becomes inevitable.

Meta-analytic evidence suggests that work-family conflict has a significant negative effect on job satisfaction and this effect is more pronounced for female employees (Kossek and Ozeki, 1998). Thus, taking into account the prevalence of work-family conflict and its effect on job satisfaction, there is a need to reconsider the factors that might help either resolve work-family conflict or, enhance job satisfaction among single mother employees. The factors considered in this present study were perfectionism and locus of control.

Perfectionism consists of two independent dimensions --positive and negative dimensions, namely adaptive and maladaptive perfectionism (Slaney et al., 2001; Stumpf and Parker, 2000). This present study focuses on maladaptive perfectionism. Maladaptive perfectionism is characterized by high personal standards and order and a perceived large discrepancy between high standards and perceived performance (Slaney et al., 2001).

Although there is a growing number of resesarch on work-family conflict and the theoretical development of the interface of work and family roles, less emphasis has been given to the role of dispositional factors including personality as antecedents of workfamily conflict (Eby et al., 2005). The few studies conducted on dispositional studies include those by Bruck and Allen (2003) and Wayne et al. (2004) who found that neuroticism was positively related to both family interference with work and work interference with family. Bruck and Allen (2003) found that neuroticism was positively related to strain-and timebased forms of work-family conflict which implies that those with increasing tendencies towards maladjustment and emotional instability are also experiencing greater work-family conflict. In their study, agreeableness was negatively related to timebased work- to- family conflict and conscientiousness with family-to-work conflict. Wayne et al. (2004) found that both the personality traits of agreeableness and conscientiousness had the tendency to reduce work interference with family and conscientiousness the tendency to reduce family interference with work. These results indicate that those who are helpful and good-natured tend to experience less time-based workfamily conflict. Individuals who have a tendency to plan and be organized experience fewer occurrences of family interference with work conflict and vice versa. Bruck and Allen (2003) also found a positive relationship between negative affectivity and strainbased work-family conflict.

Research on personality factors does provide an understanding of how employees with different traits respond differentially to conflict between work and family roles. However, consideration of personality factors such as affectivity and conscientiousness are still at the initial stage of investigation. As noted by Mitchelson (2009), knowing how work-family conflict differs by these general personality factors provides initial evidence necessary to identify more specific personality traits such as perfectionism that may play a larger role in how workfamily conflict is perceived and reconciled.

Of the few research conducted on the relationship between perfectionism and work-family conflict, Beauregard (2006) found a significant positive relationship between maladaptive perfectionism and work-family conflict. Similar findings were reported by Mitchelson (2009) whose findings indicate that those with maladaptive perfectionism tend to have higher strain and time-based family interference with work and higher behaviour-based work interference with family, compared with adaptive perfectionists.

Another dispositional factor that bears relationships with work-family conflict and job satisfaction is locus of control. Locus of control is a stable personality trait which reflects beliefs concerning the degree to which an individual has control over various aspects of their lives and more specifically, it refers to an individual's perception of the locus of events as determined internally by his/her own behavior versus fate, luck, or external circumstances (Rotter, 1966).

Several studies have examined the direct effect of locus of control on work-family conflict. Noor (2002; 2006) found that a greater intensity of work-family conflict was experienced by individuals with an external locus of control whereby these individuals attribute the causes of events in their lives to factors other than themselves. Similarly Andreassi and Thompson (2007) and Noryati et al. (2009) found that internal locus of control was negatively related to workfamily conflict.

Studies have shown that work-family conflict could directly decrease employees' job satisfaction (Karatepe and Uludag, 2007; Namasivayam and Zhao, 2007; Yildirim and Aycan, 2008; Lapierre et al., 2008; Lu et al., 2008). Employees experiencing work-family conflict, involving incompatible demands from work 
and family domains, would blame their organizations for depleting the time and energy they need for performing family roles and thus be less satisfied with their jobs.

Research model: The model in this study was developed based on the Conservation of Resources (COR) theory (Hobfoll, 1989) besides the work of previous researchers. The COR theory proposes that individuals seek to acquire and maintain resources to reduce stress. Personal characteristics like internal locus of control are resources which buffer one against stress. Loss of these resources, or the threat of such a loss, may cause the experience of stress and work-family conflict is a form of stress. This conflict could in turn lead to strain because resources are lost in the process of juggling lead to strain because resources are lost in the process of juggling both work and family roles. The loss of these resources results in job dissatisfaction.

Similarly, the absence of a positive aspect of perfectionism may also lead to work-family conflict. Based on the COR theory (Hobfoll, 1989), one could argue that changes in the level of maladaptive perfectionism could lead to changes in the levels of work-family conflict as well as the levels of job satisfaction. Also, changes in the level of locus of control could lead to changes in the levels of workfamily conflict as well as the levels of job satisfaction.

Based on the COR theory and previous research findings discussed earlier, we develop and test a research model that investigates the indirect effects of perfectionism and locus of control on job satisfaction through work-family conflict (Fig. 1). In this study we tested the following hypotheses:

H1: There is a significant positive relationship between maladaptive perfectionism and work-family conflict

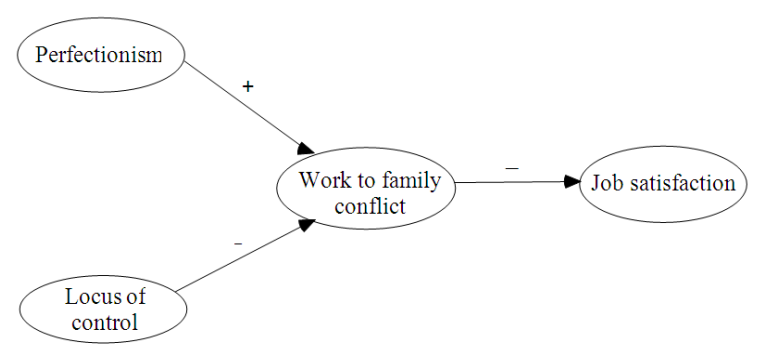

Fig. 1: Research model
$\mathrm{H} 2$ : There is a significant negative relationship between internal locus of control and work-family conflict.

H3: There is a significant negative relationship between work-family conflict and job satisfaction

H4: Perfectionism has an indirect effect on job satisfaction through work-family conflict

H5: Internal locus of control has an indirect effect on job satisfaction through work-family conflict

\section{MATERIALS AND METHODS}

Sample and procedure: The sample of this present study consisted of single mothers working in Klang Valley, Malaysia. Single mother employees who meet the following criteria were identified: (a) married, (b) working full-time and (c) has at least one child staying at home. These criteria were established to ensure that the women in the sample had quite similar responsibilities in terms of family and work roles. Data were collected from a sample of 159 single mother employees using self-administered questionnaires through the drop and collect method. The questionnaire was administered in the Malay language. Before its administration, the questionnaire was translated into Malay and was validated by back-translation to ensure that both versions were equivalent. To check for clarity, understanding and suitability of the items in the Malaysian context a pilot test of the questionnaire was conducted. Modifications to the original items were made based on the feedback provided by 15 employed mothers during the pilot test.

Measurement perfectionism: Maladaptive perfectionism was assessed using the discrepancy subdimension scale consisting of 12 items from the Almost Perfect Scale -Revised (APS-R) by Slaney et al. (2001). This scale assessed the extent to which individuals perceived large discrepancy between their personal standards and their performance. Examples of items are: "I am never satisfied even when I know I have done my best" and "My performance rarely measures up to my standards". Items with factor loadings less than 0.50 were deleted.

Locus of control: The Spheres of Control scale developed by Paulhus (1983) was used to measure locus of control. This study is limited to measuring employees' personal efficacy and uses seven items depicting internal locus of control. Examples of items are: "I usually do not set goals because I have a hard time following through them" and "I can learn almost anything if I set my mind to it". Items with factor loadings less than 0.50 were deleted. 
Work-family conflict: Eight items from Pleck et al. (1980) were used to measure work-family conflict. Sample items included "My work takes up time that I'd like to spend with my family" and "After work, I come home too tired to do some of the things I would like to do". Items with factor loadings less than 0.5 were deleted.

Job satisfaction: Three items from Hackman and Oldhman (1975) and two by Clark (2001) were used to measure job satisfaction. Sample items included "I am generally satisfied with the kind of work I do in this job" and "I frequently think of quitting this job". Items with factor loadings less than 0.5 were deleted.

Analysis of hypothesized model: A structural equation modeling analysis was used to estimate the direct and indirect effects of perfectionism and locus of control on job satisfaction of single mother employees. The hypothesized model was tested with AMOS 16 using maximum likelihood estimation. The structural equation modeling analysis was conducted using a twophase approach, i.e., measurement model analysis and structural model analysis (Hair, 2006; Kline, 2005; Byrne, 2009).

In the first phase, a confirmatory factor analysis was performed to measure the adequacy of the measurement model. During this phase, the overall model fit, the reliability and validity of the measurement model was assessed. The reliability was measured using Cronbach's alpha reliability coefficient to determine the internal consistency of the latent constructs. Hair, (2006) suggested 0.7 as the minimum acceptable Cronbach's alpha value. The reliabilities of the variables also indicate the convergent validities of the variables (Hair, 2006).

In the second phase, the structural model analysis was performed to investigate the structural relationship among the latent constructs (Kline, 2005). Goodnessof-model fit in both the phases was judged using multiple indices, namely, Root-Mean-Square Error of Approximation (RMSEA), Goodness-of-Fit Index (GFI), Non-Normed Fit Index (NNFI) also known as the Tucker-Lewis Index (TLI), Comparative Fit Index (CFI) and the Parsimonious Goodness-of-Fit Index (PGFI). These measures were chosen as they enable an assessment of absolute fit (RMSEA, GFI), comparative fit between the target model and the independence model (TLI, CFI). A RMSEA coefficient of .08 is normally taken as indicative of satisfactory model fit and one of .05 as showing very good fit (Steiger, 1990). For the GFI, TLI and CFI, coefficients of .90 but preferably higher are normally taken as indicative of model fit (Byrne, 2009). Meanwhile, for PGFI, parsimony fit indices within the region of .50 or above suggests a good model fit (Mulaik et al., 1989).

\section{RESULTS}

The respondents' age ranged from 31 to 45 years $(\mathrm{M}=37.13, \mathrm{SD}=6.07)$ with $62.3 \%$ aged $36-45$. They had an average of about 9 years of working experience $(\mathrm{M}=9.41, \mathrm{SD}=6.41)$. About $60 \%$ of the respondents had only one to two children and on the average, the respondents had 2-3 children $(\mathrm{M}=2.48, \mathrm{SD}=1.34)$.

Table 1 shows the means, standard deviations and reliabilities of the variables and the correlation coefficients between these variables. The bivariate correlation analyses produce correlation coefficients that are significant for the relationships between maladaptive perfectionism and locus of control and work-family conflict, locus of control and job satisfaction and workfamily conflict and job satisfaction.

The overall fit indices for the CFA model were acceptable (Table 2), with $\chi^{2} / \mathrm{df}=1.84$, RMSEA $=0.07$, $\mathrm{CFI}=0.91, \mathrm{GFI}=0.86$, TLI $=0.90$. All the fit indices for the initial CFA model indicated an acceptable fit to the data (Schumarker and Lomax, 2010; Kline, 2005).

Our proposed structural model yielded good fit to the data, with a chi-square $(213.90, \mathrm{p}<0.001)$ to degrees of freedom (115) ratio of 1.86 (Table 3). A TuckerLewis Index (TLI) value of .90 is at the minimally acceptable value of .90 (Kline et al., 2005). The rootmean-square error of approximation (RMSEA) value of 0.07 is within the acceptable range from $0.00-0.08$ (Ho, 2006) which suggests that the fit of the model is adequate. Fig. 2 presents the standardized path coefficients linking the variables in our model. The path coefficients in this model indicate that maladaptive perfectionism is positively linked to work-family conflict, internal locus of control is negatively linked to work-family conflict and work-family conflict is negatively linked to job satisfaction. These results provide support for $\mathrm{H} 1, \mathrm{H} 2$ and $\mathrm{H} 3$.

Table 1: Means, standard deviations, reliabilities and correlations

\begin{tabular}{llllllll}
\hline Latent variables & $\mathrm{M}$ & S.D. & $\alpha$ & 1 & 2 & 3 & 4 \\
\hline Work-Family Conflict & 2.89 & 0.908 & 0.802 & 1.000 & & & \\
Job Satisfaction & 3.94 & 0.753 & 0.783 & $-0.427^{* *}$ & 1.000 & 1.000 \\
Locus of Control & 3.39 & 0.820 & 0.750 & $-0.333^{* *}$ & $0.300^{* *}$ & $-0.196^{*}$ & 1 \\
Perfectionism & 3.02 & 0.743 & 0.902 & $0.408^{* *}$ & -0.127 &
\end{tabular}


Am. J. Applied Sci., 8 (11): 1107-1115, 2011

Table 2: Summary of model fit indices for CFA model

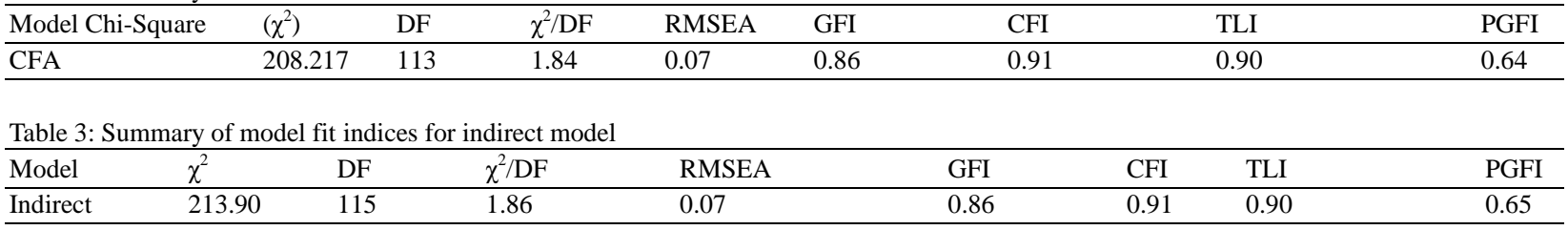

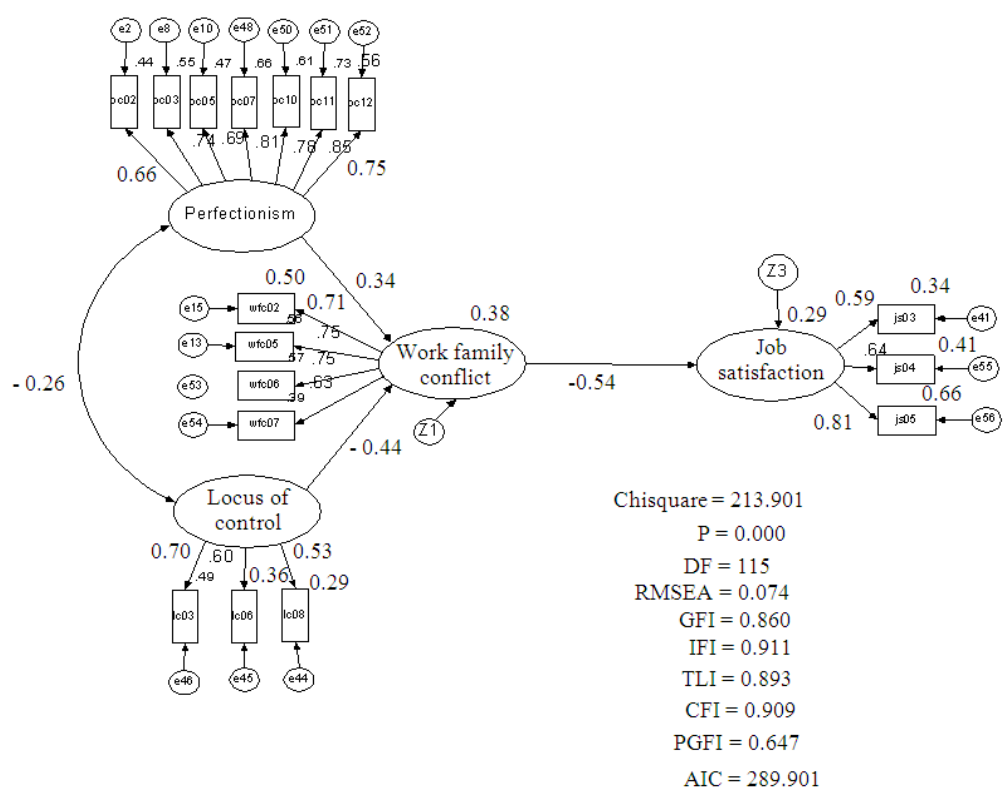

Fig. 2: Standardized path coefficients of the model

Our proposed structural model yielded good fit to the data, with a chi-square $(213.90, \mathrm{p}<0.001)$ to degrees of freedom (115) ratio of 1.86 (Table 3). A TuckerLewis Index (TLI) value of 0.90 is at the minimally acceptable value of 0.90 (Kline, 2005; Vandenberg and Lance, 2000). The Root-Mean-Square Error of Approximation (RMSEA) value of 0.07 is within the acceptable range from 0.00-0.08 (Ho, 2006) which suggests that the fit of the model is adequate. Figure 2 presents the standardized path coefficients linking the variables in our model. The path coefficients in this model indicate that maladaptive perfectionism is positively linked to work-family conflict, internal locus of control is negatively linked to work-family conflict and work-family conflict is negatively linked to job satisfaction. These results provide support for $\mathrm{H} 1, \mathrm{H} 2$ and $\mathrm{H} 3$.

As expected, the modeling results showed that perfectionism and locus of control were significantly related to work-family conflict and that work-family conflict in turn was related to job satisfaction. The results support the indirect path between locus of control and job satisfaction through work-family conflict. The indirect path between maladaptive perfectionism and job satisfaction through work-family conflict was also supported. According to the squared multiple correlations for this hypothesized model, $29 \%$ of the variance in job satisfaction is accounted for by maladaptive perfectionism, internal locus of control and work-family conflict.

The significant paths linking perfectionism, locus of control and work-family conflict to job satisfaction, combine with our model's satisfactory fit index values, are consistent with the expectation that perfectionism and locus of control are indirectly related to job satisfaction through work-family conflict. These results provide support for $\mathrm{H} 4$ and $\mathrm{H} 5$.

\section{DISCUSSION}

The significant relationship between perfectionism and job satisfaction is consistent with the results reported by Beauregard (2006) and Mitchelson (2009).

The results indicate that employees who are maladaptive perfectionists tend to experience greater conflict between work and family roles. According to 
maladaptive perfectionists are less capable to manage conflict between work and family domains as compared to adaptive perfectionists. It could be useful to understand the coping mechanisms perfectionists use to manage work-family conflict so that employees could benefit from such mechanisms.

With regard to locus of control and its association with work-family conflict, this study found that an increase in locus of control led to a decrease in workfamily conflict. These findings are consistent with the findings of Noor $(2002 ; 2006)$. The significant effect of locus of control and work-family conflict also supports the results of a study by Andreassi and Thompson (2007). In other words, single mothers who believe that they are in control of the events that happen in their lives seem to be more satisfied with their jobs and seem to experience less work-family conflict.

The significant direct relationships between workfamily conflict and job satisfaction are consistent with the results of previous research (Lu et al., 2008) whereby individuals who reported higher intensities of work-family conflict tended to experience lower levels of job satisfaction. Similar findings have also been reported by Namasivayam and Zhao (2007); Karatepe and Uludag (2007) and Yildirim and Aycan (2008).

With regard to the indirect effect of work-family conflict in the relationship between locus of control and job satisfaction, the results show that single mother employees with internal locus of control tend to experience lower intensity of conflict and this would in turn increase their levels of job satisfaction. Similar findings have been reported by Noor (2002). Single mother employees who believe that they are in control of the events that happen in their lives seem to experience less work-family conflict and consequently seem to be more satisfied with their jobs. The indirect effect of perfectionism on job satisfaction indicates that employees with chronic tendencies to strive for excellence tend to experience greater intensities of conflict between work and family roles. With the experience of greater work-family conflict, they tend to blame their organizations for having depleted the time and energy they need for participating in family activities and thus are less satisfied with their jobs.

The findings of this study are in accordance with the COR theory which proposes that individuals seek to acquire and maintain resources to reduce stress. Personal characteristics like internal locus of control and adaptive perfectionism are resources which buffer one against stress. Loss of these resources would cause the experience of work-family conflict which is a form of stress. On the other hand, the ability to balance the demands of work and family roles is a resource which could buffer one against stress. Loss of this resource could lead an employee to experience job dissatisfaction.

\section{CONCLUSION}

In conclusion, this research established the indirect effects of maladaptive perfectionism and locus of control on job satisfaction through work-family conflict. The results verify that maladaptive perfectionism and external locus of control could result in greater work-family conflict which in turn could reduce the level of job satisfaction.

The findings of this study have important implications for organizations. The findings demonstrate that perfectionism and locus of control are important individual resources that are related to employees' experiences of work-family conflict and job satisfaction. Raising managerial awareness of the influence of personality traits upon the experience of work-family conflict may prove useful. It is well documented that managerial support of work-home issues is associated with lower levels of employee work-family conflict (Wadsworth and Owens, 2007). A manager who is aware of the influence of personality traits would provide support that takes into consideration such traits instead of focusing only on situational characteristics such as work hours or demands from family. Employers should look into the possibility of designing training programmes to assist employees in taking more control of events in their work situations. Another possibility is to consider selecting potential employees who are adaptive perfectionist and those with internal locus of control. So it will be prudent to include a way to assess an individual's personality as part of the selection process since as noted by Hurtz and Donovan (2000), perfectionism should be of interest to employers as it is the employees with demanding standards and higher thresholds for performance who often represent ideal employees in many organizations. Additionally, an individual's perception of his or her control beliefs should also be assessed as part of the selection process. Future research should also examine other personality factors that could reduce employees' exposure to workfamily conflict and hence increase their job satisfaction. For example, egalitarian gender role orientation and self-esteem are likely to reduce work-family conflict. There is also a need for future researchers to test an expanded model with the inclusion of other dispositional factors.

The strength of this study lies in the design which allows for a close examination of the mechanisms through which the dispositional factors of maladaptive 
perfectionism and locus of control affect the level of job satisfaction among single mother employees by controlling, through sample selection, for age of mothers, employment status and presence of a child. However the selection of this sample also results in limitations to this study.

First, a significant limitation is the small sample size that was utilized. The results reported here may only be generalized to single mothers meeting the selection criteria (full-time working, aged 45 years and below and having at least one child). Caution must be exercised in generalizing the findings from this sample to other single can only be answered by using longitudinal data. mother employees in the study area, as well as to other groups of women employees such as those with partners and working part-time, as well as those without children. Second, besides limitations due to the nature of the sample, the inferences drawn from this study are limited by self-report data thus exposing the results to interpretation of method variance (Doty and Glick, 1998). Third, the cross-sectional characteristics of the data do not allow us to draw firm conclusions in terms of causality. The direction of causality

\section{REFERENCES}

Ahmad, A. and Z. Omar, 2008. Gender differences in work-family conflict and family-friendly employment policy practices. Int. J. Hum., 6: 1525.

Ahmad, A. and Z. Omar, 2010. Perceived workplace culture as an antecedent of job stress: The mediating role of work-family conflict. J. Soc. Sci., 6: 369-375. DOI: 10.3844/jssp.2010.369.375

Ahmadi, K. and K. Alireza, 2007. Stress and Job Satisfaction among Air Force Military Pilots. Journal of Social Sciences, 3: 159-163. DOI: 10.3844/jssp.2007.159.163

Andreassi, J.K. and C.A. Thompson, 2007. Dispositional and situational sources of control: Relative impact on work-family conflict and positive spillover. J. Managerial Psychology, 22: 722-740. Doi: 10.1108/02683940710837697

Beauregard, T.A., 2006. Predicting interference between work and home: A comparison of dispositional and situational antecedents. J. Managerial Psychol., 21: 244-264. DOI: $10.1108 / 02683940610659588$

Bergman, B., F. Ahmad and D.E. Stewart, 2008. Work family balance, stress and salivary cortisol in men and women academic physicians. Int. J. Behavioral Med., 15:54-61. DOI: 10.1007/BF03003074
Bruck, C.S. and T.D. Allen, 2003. The relationship between big five personality traits, negative affectivity, type A behavior and work-family conflict. J. Vocat. Behavior, 63: 457-472. DOI: 10.1016/S0001-8791(02)00040-4

Byrne, B.M., 2009. Structural equation modeling with AMOS: Basic concepts, applications and programming. 2nd Edn., Routledge, New York, ISBN-10: 0805863729, pp: 396.

Chen, G., R.E. Ployhart, H.C. Thomas, N.B. Anderson and D. Paul, 2011. The power of momentum: A new model of dynamic relationships between job satisfaction change and turnover intentions. Acad. Manage. J., 54: 159-181. DOI: 10.5465/AMJ.2011.59215089 PMID: 59215089

Clark, S.C., 2001. Work cultures and work/family balance. J. Vocational Behav., 58: 348-365. DOI: 10.1006/jvbe.2000.1759

Doty, D.H. and W.H. Glick, 1998. Common methods bias: Does common methods variance really bias results? Organiz. Res. Methods, 1: 374-406. DOI: 10.1177/109442819814002

Eby, L.T., W.J. Casper, A. Lockwood, C. Bordeaux and A. Brinley, 2005. Work and family research in IO/OB: Content analysis and review of the literature (1980-2002). J. Vocat. Behav., 66: 124197. DOI: $10.1016 /$ j.jvb.2003.11.003

Gordon, J.R., K.S. Whelan-Berry and E.A. Hamilton, 2007. The relationship among work-family conflict and enhancement, organizational work-family culture and work outcomes for older working women. J. Occupat. Health Psychol., 12: 350-364. DOI: $10.1037 / 1076-8998.12 .4 .350$

Hackman, J.R. and G.R. Oldham, 1975. Development of the job diagnostic survey. J. Applied Psychol., 60: 159-170. DOI: 10.1037/H0076546

Hair, J.F., 2006. Multivariate Data Analysis. 6th Ed., Pearson Prentice Hall, Upper Saddle River, N.J., ISBN: 0130329290, pp: 899.

Hill, E.J., C. Yang, A.J. Hawkins and M. Ferris, 2004. A cross-cultural test of the work-family interface in 48 countries. J. Marriage Family, 66: 1300-1316. DOI: 10.1111/j.0022-2445.2004.00094.x

Ho, R., 2006. Handbook of Univariate and Multivariate Data Analysis and Interpretation with SPSS. 1st Edn., Chapman and Hall/CRC, Boca Raton, ISBN: 1584886021 , pp: 406.

Hobfoll, S.E., 1989. Conservation of resources: A new attempt at conceptualizing stress. Am. Psychologist, 44: 513-524. DOI: 10.1037/0003066X.44.3.513 
Howard, W.G., H.H. Donofrio and J.S. Boles, 2004. Inter-domain work-family, family-work conflict and police work satisfaction. Policing: Int. J. Police Strategies Manag., 27: 380-395. DOI: $10.1108 / 13639510410553121$

Hurtz, G.M. and J.J. Donovan, 2000. Personality and job performance: The Big Five revisited. J. Applied Psychol., 85: 869-879. DOI: 10.1037//00219010.85.6.869

Karatepe, O.M. and O. Uludag, 2007. Conflict, exhaustion and motivation: A study of frontline employees in Northern Cyprus hotels. Int. J. Hospitality Manage., 26: 645-665. DOI: 10.1016/j.ijhm.2006.05.006

Kline, R.B., 2005. Principles and Practice of Structural Equation Modeling. 2nd Ed., Guilford Press, New York, ISBN: 1593850751, pp: 366.

Kossek, E.E. and C. Ozeki, 1998. Work-Family conflict, policies and the job-life satisfaction relationship: A review and directions for organizational behavior-human resources research. J Applied Psychol., 83: 139-149. DOI: 10.1037//0021-9010.83.2.139

Lapierre, L.M., P.E. Spector, T.D. Allen, S. Poelmans and C.L. Cooper et al., 2008. Family-supportive organization perceptions, multiple dimensions of work-family conflict and employee satisfaction: A test of model across five samples. J. Vocat. Behav., 73: 92-106. DOI: 10.1016/j.jvb.2008.02.001

Lu, L., S.F. Kao, T.T. Chang, H.P. Wu and C.L. Cooper, 2008. Work/family demands, work flexibility, work/family conflict and their consequences at work: A national probability sample in Taiwan. Int. J. Stress Manage., 15: 1-21. DOI: 10.1037/1072-5245.15.1.1

Mitchelson, J.K., 2009. Seeking the perfect balance: Perfectionism and work-family conflict. J. Occupat. Organiz. Psychol., 82: 349-367. DOI: 10.1348/096317908X314874

Mulaik, S.A., L.R. James, J.V. Alstine, N. Bennet and S. Lind et al., 1989. Evaluation of goodness-of-fit indices for structural equation models. Psychol. Bull., 105: 430-445. DOI: 10.1037/00332909.105.3.430

Namasivayam, K. and X. Zhao, 2007. An investigation of the moderating effects of organizational commitment on the relationships between workfamily conflict and job satisfaction among hospitality employees in India. Tourism Manage., 28: 1212-1223. DOI: 10.1016/j.tourman.2006.09.021
Noor, N.M., 2002. Work-Family Conflict, Locus of control and women's weil-being: Tests of alternative pathways. J. Soc. Psychol., 142: 645662. DOI: 10.1080/00224540209603924

Noor, N.M., 2006. Malaysian women's state of wellbeing: Empirical validation of a conceptual model. J. Soc. Psychol., 146: 95-115. DOI: 10.3200/SOCP.146.1.95-115

Noryati N., A. Aminah and B. Maznah, 2009. The mediating effect of work-family conflict on the relationship between locus of control and job satisfaction. J. Soc. Sci., 5: 348-354. DOI: $10.3844 /$ jssp.2010.369.375

Paulhus, D., 1983. Sphere-specific measures of perceived control. J. Personality Social Psychology, 44: 1253-1265. DOI: 10.3844/jssp.2009.348.354

Pleck, J.H., G.L. Staines and L. Lang, 1980. Conflict between work and family life. Monthly Labor Rev.

Rehman, M.S., 2011. An empirical study of impact of job satisfaction on job performance in the public sector organizations. Interdisciplinary J. Contemp. Res. Bus.

Rotter, J.B., 1966. Generalized expectancies for internal versus external control of reinforcement. Psychol. Monogr., 80: 1-28. PMID: 5340840

Schumarker, R.E. and R.G. Lomax, 2010. A Beginner's Guide to Structural Equation Modeling. 3rd Edn., Taylor and Francis, New York, ISBN-10: 1841698911, pp: 510.

Slaney, R.B., K.G. Rice, M. Mobley, J. Trippi and J.S. Ashby, 2001. The revised almost perfect scale. Measur. Evaluat. Counsel. Devel., 34: 130-145.

Steiger, J.H., 1990. Structural model evaluation and modification: An interval estimation approach. Multivariate Behav. Res., 25: 173-180. DOI: 10.1207/s15327906mbr2502_4

Stumpf, H. and W.D. Parker, 2000. A hierarchical structural analysis of perfectionism and its relation to other personality characteristics. Persona. Indiv. Diffe., 28: 837-852. DOI: 10.1016/S0191-8869(99)00141-5

Vandenberg, R.J. and C.E. Lance, 2000. A review and synthesis of the measurement invariance literature: Suggestions, practices and recommendations for organizational research. Organiz. Res. Methods, 3: 4-70. DOI: $10.1177 / 109442810031002$

Wadsworth, L.L. and B.P. Owens, 2007. The effects of social support on work-family enhancement and work-family conflict in the public sector. Public Adminis. Rev., 67: 75-87. DOI: 10.1111/j.15406210.2006.00698.x 
Wayne, J.H., N. Musisca and W. Fleeson, 2004. Considering the role of personality in the workfamily experience: Relationships of the big five to work-family conflict and facilitation. J. Vocational Behav., 64: 108-130. DOI: 10.1016/S00018791(03)00035-6

Yahaya, A., N. Yahaya, K. Arshad, J. Ismail and S. Jaalam et al., 2009. Occupational stress and its effects towards the organization management. J. Soc. Sci., 5: 390-397. DOI: 10.3844/jssp.2009.390.397
Yildirim, D. and Z. Aycan, 2008. Nurses' work demands and work-family conflict: A questionnaire survey. Int. J. Nurs. Stud., 45: 13661378. DOI: 10.1016/j.ijnurstu.2007.10.010 